\title{
Importance of tumor location and histology in familial risk of upper gastrointestinal cancers: a nationwide cohort study
}

This article was published in the following Dove Press journal:

Clinical Epidemiology

\author{
Elham Kharazmi 1,2* \\ Masoud Babaei ${ }^{1,3 *}$ \\ Mahdi Fallah ${ }^{2}$ \\ Tianhui Chen ${ }^{1,4}$ \\ Kristina Sundquist ${ }^{5,6}$ \\ Kari Hemminki ${ }^{1,5}$ \\ 'Division of Molecular Genetic \\ Epidemiology, German Cancer \\ Research Center (DKFZ), Heidelberg, \\ Germany; ${ }^{2}$ Division of Preventive \\ Oncology, National Center for Tumor \\ Diseases, Heidelberg, Germany; \\ ${ }^{3}$ Digestive Oncology Research Center, \\ Digestive Diseases Research Institute, \\ Tehran University of Medical Sciences, \\ Tehran, Iran; ${ }^{4}$ Group of Molecular \\ Epidemiology and Cancer Precision \\ Prevention, Institute of Occupational \\ Diseases, Zhejiang Academy of \\ Medical Sciences (ZJAMS), Hangzhou, \\ People's Republic of China; ${ }^{5}$ Center \\ for Primary Health Care Research, \\ Lund University, Malmö, Sweden; \\ ${ }^{6}$ Stanford Prevention Research \\ Center, Stanford University School of \\ Medicine, Stanford, CA, USA \\ *These authors contributed equally to \\ this work
}

Correspondence: Elham Kharazmi Division of Preventive Oncology, German Cancer Research Center (DKFZ), Im Neuenheimer Feld 58I, Heidelberg 69120, Germany

Tel +496221423040

Fax+49622I565231

Email e.kharazmi@dkfz.de
Background: Familial clustering of upper gastrointestinal (UGI) cancers and the significance of family history has been addressed previously. We aimed to elucidate the familial risk based on the specified tumor location and histology.

Method: In the Swedish Family-Cancer Database, we determined the familial risk of UGI cancer patients diagnosed (1958-2015) with esophageal and gastric cancer by tumor location using standardized incidence ratios (SIRs).

Results: Risk of esophageal cancer in first-degree relatives (FDRs) of patients with esophageal cancer increased 2.4-fold (SIR 95\% CI 2.0-2.8), whereas risk of esophageal cancer in cases with family history of cancer in the middle third of the esophagus increased 3.4-fold (SIR 95\% CI 2.1-5.1). Risk of gastric cancer in FDRs increased 1.6-fold (SIR 95\% CI 1.5-1.7), occurrence of concordant subsite gastric cancer in the antrum, body, and cardia was 5.5-fold (SIR 95\% CI 2.4-11), 4.6-fold (SIR 95\% CI 2.6-7.4), and 1.7-fold (SIR 95\% CI 1.1-2.5), respectively. Familial risk of concordant histological subtype in esophageal cancer was 4.1-fold for squamous cell carcinoma (SIR 95\% CI 3.2-5.2) and 3.6-fold for adenocarcinoma (SIR 95\% CI 2.5-5.1). The risk of concordant gastric adenocarcinoma was 1.6-fold for one affected FDR (SIR 95\% CI 1.5-1.7), 6.1-fold for two FDRs (SIR 95\% CI 4.4-8.4), and 8.6-fold among twins (SIR 95\% CI 2.3-22).

Conclusion: Family history of cancer in the lower third of the esophagus and stomach cancer in specific locations such as the antrum, body, and cardia can be considered as important predictive evidence for cancer in the same location in relatives. Our findings might guide endoscopy-based surveillance by introducing subgroups of populations with a higher risk for UGI cancer with particular attention to concordance of location of lesions, which could be a reasonable strategy for early detection, and thus help save more lives.

Keywords: familial risk, gastric cancer, stomach cancer, esophageal cancer, anatomic location, histology

\section{Plain language summary}

If a close relative has cancer in the upper part of the digestive system - that is, esophagus or stomach - the risk of such cancers in other relatives is higher than in the general population. However, it was unknown whether the familial risk is different if we go into further details of tumor in terms of the anatomical parts of the esophagus (upper, middle, or lower thirds) or stomach or details of histology of cancer - that is, the way tumor cells look under the microscope.

In this study, we used the world's largest database that has both a family relationship database and cancer information for all the study participants (all Swedes born after 1931) and their first-degree relatives (FDRs; parents, brothers/sisters, and children).

Family history of cancer in the lower third of esophagus and stomach cancer in specific locations such as the antrum (the near exit chamber of stomach), body, and cardia (the entrance part 
of stomach) can be considered as important predictive evidence for cancer in the same location in close relatives. Moreover, we found that if a relative has a specific cancer histology, the risk of getting the same type of cancer in other close relatives is higher.

Our findings might guide endoscopy-based examinations of the upper part of the digestive system by introducing subgroups of populations with a higher risk for such cancers, with particular attention to similarity of location and cell type of tumors, which could be a reasonable strategy for early detection and thus help save more lives.

\section{Introduction}

Esophageal and gastric cancers are considered to be two of the most common malignancies worldwide. ${ }^{1}$ Esophageal cancer is the third most common cancer of the digestive tract and the seventh leading cause of cancer-related deaths worldwide. ${ }^{2}$ This cancer has a very poor prognosis, and its mortality closely follows its incidence. ${ }^{1,3}$ Gastric cancer, with more than one million estimated new cases per year, is the fourth most commonly occurring cancer. Despite the steady decline in the incidence of gastric cancer over the past 60 years, it remains the second leading cause of cancer deaths worldwide. ${ }^{3}$ In contrast with the well-established declining trends seen in most countries and regions of the world, the burden of gastric cancer appears to be increasing in several indigenous populations. ${ }^{4}$ In most Western countries, the 5-year survival rate of patients with gastric cancer has not improved despite emerging recent innovations in the treatment modalities. Gastric cancer has been always associated with a poor prognosis due to its late clinical manifestations; therefore, advanced stages of tumor at initial diagnosis would result in the treatment being substantially less effective. Implementing endoscopic and radiographic screening programs for upper gastrointestinal (UGI) cancers was considered to be an effective strategy for controlling the burden of these cancers in high-incidence areas. ${ }^{5,6}$ However, in low- to moderate-incidence areas (e.g., European and other Western countries) any screening of UGI cancer does not seem to be cost-effective, and more data are required to justify any screening implementation. Therefore, future UGI cancer endoscopy-based surveillances should be guided by risk-stratification assessment and identification of population subgroups with a higher risk for UGI cancer, which could be a reasonable strategy for early detection and thus help save more lives. ${ }^{7}$

Anatomically, gastric cancer can be divided into two groups: "cardia" cancer (the upper third around the cardia) and "non-cardia" cancer (middle body, antrum, and pylorus) ${ }^{8}$ Based on results from observational studies, cardia and noncardia gastric cancers are two different diseases with different epidemiological behaviors and distinct etiologies. ${ }^{9,10}$ The major risk factors of cardia gastric cancer are obesity and gastroesophageal reflux disease (GERD). ${ }^{11}$ Although both of these risk factors may have some rare genetic predispositions, they are mainly assumed to be environmental risk factors related to Western lifestyle habits. ${ }^{2}$ Barrett's esophagus known as a precancerous condition that increases the risk of lower esophageal adenocarcinoma - is also related to obesity and GERD. ${ }^{12}$ The other evidence that may attest to the importance of environmental factors in the development of UGI cancers is geographic variations and temporal changes in the incidence of these diseases ${ }^{13}$ and sharing of risk among spouses. ${ }^{14}$

The vast majority of these cancers appear in a sporadic setting; ${ }^{15}$ however, epidemiological studies have already shown a two- to three-fold higher risk of esophageal ${ }^{16}$ and gastric $^{17}$ cancers among first-degree relatives (FDRs) of patients with these diseases. We aimed to elucidate the importance of tumor location and histology in the familial risk of UGI cancers to identify high-risk subgroups. To achieve this goal, we used the Swedish Family-Cancer Database (FCD), which is the largest FCD of its kind in the world and is free from biases of case-control studies.

\section{Material and methods}

Swedish FCD contains data on individuals born in Sweden from 1932 to 2015 with that of their biological parents. This database includes population-based data from multigenerational registries, national censuses (1960, 1970, 1980, and 1990), the Swedish Cancer Registry, and death notifications (Cause of Death Register). ${ }^{18}$ The data completeness of the FCD has been reported to be close to $90 \%$, with approximately two million registered first primary invasive cancers. ${ }^{18,19}$

Data on all UGI cancer patients registered from 1958 to 2015 and their FDRs were extracted. Those without any identified FDRs were excluded from this study. A four-digit diagnostic code according to the seventh revision of the International Classification of Diseases (ICD-7) has been available since 1958 to define the topography (primary site) of tumors in our data. The ICD-7 Code 150 was used for esophageal cancer, and Code 151 for gastric cancer. For esophageal cancer, the tumor locations were defined as upper third, middle third, and lower third of esophagus and, for gastric cancer, as the cardia, fundus, body, antrum, and pylorus of stomach. In this study, we included data on all patients with esophageal and gastric cancer with either invasive or noninvasive (e.g., in situ) tumors recorded in the Swedish Cancer Registry. 
Furthermore, analyses after exclusion of noninvasive cases, which constituted $3 \%$ and $5 \%$ of patients with gastric and esophageal tumor, respectively, are provided (Tables S1-S4).

Histological subtypes of esophageal tumors were defined on the basis of the Pathological Anatomic Diagnosis (PAD) code from 1958 to 1992 and the third version of the International Classification of Diseases coding system for Oncology (ICD-O-2/3) from 1993 onward. Invasive UGI tumors are defined as tumors with Behavior Code 3 in their fifth digit of the ICD-O-2/3 morphology code (regardless of TNM stage or tumor grade), or Behavior Code 6 in their third digit of the PAD code. In situ tumors are defined as tumors with Behavior Code 2 in their fifth digit of the ICD-O-2/3 morphology code or Behavior Code 4 in the third digit of the PAD code.

We used standardized incidence ratios (SIRs) for calculation of familial risk of concordant (same subsite) and discordant tumor location of UGI cancers and histological subtypes of esophageal cancer among FDRs compared to cases without family history of UGI cancer. The analyses were stratified on the basis of the location of the esophagus and stomach tumors. The follow-up was started for each subject at birth, immigration, or January 1, 1958, whichever came latest. Follow-up was terminated on death, emigration, or the closing date of the study (December 31, 2015), whichever came first. SIRs were calculated as the ratio of observed to expected number of esophagus and stomach cancer among FDRs. The expected numbers were calculated using the 5-year age-, sex-, period- (5-year bands), socioeconomic status (blue-collar worker, white-collar worker, farmer, self-employed, high income office worker/professional, or other/unspecified), and residential area (large cities, South Sweden, North Sweden, or unspecified) -specific incidence rates in those without a family history of esophagus or stomach cancer. Confidence intervals $(95 \% \mathrm{CI})$ were calculated assuming a Poisson distribution. All analyses were conducted using the SAS software version 9.4 (SAS Institute Inc., Cary, NC, USA). The study protocol for the familial cancer studies has been approved by the Ethics Committee of Lund University and the methods were carried out in accordance with the approved guidelines. As anonymized data have been used for this study, no informed consent was needed from subjects.

\section{Results}

We identified 63,980 patients with UGI cancer (13,325 esophageal and 50,655 gastric cancer patients) diagnosed between 1958 and 2015 (Table 1). Some 1,125 UGI cancer patients (974 gastric cancer and 151 esophageal cancer patients) had a positive family history of the same UGI cancer (including in situ) in at least one of their FDRs (240 familial UGI cases had a discordant UGI cancer). Esophageal cancers are more likely to occur in men as compared to women in both familial (70\%) and sporadic cases (74\%). Mean age at diagnosis in patients with familial esophageal cancer was approximately 3 years younger than that in sporadic ones ( $P$-value 0.013$)$. Among patients with esophageal cancer, the lower third of esophagus was the most frequent tumor location in both familial $(65 \%$ out of specified locations) and sporadic cases ( $68 \%$ out of specified locations). Furthermore, our data showed that the occurrence of tumors in the middle third of esophagus was more common in patients with familial, rather than sporadic, esophageal cancer ( $27 \%$ versus $21 \%$; Table 1 ).

The mean age at diagnosis in patients with familial gastric cancer was approximately 4 years younger than that in sporadic ones $(P$-value $<0.001$; Table 1$)$. Among patients with gastric cancer, the cardia was the most frequent tumor location in both familial ( $42 \%$ out of specified locations) and sporadic (48\%) cases (Table 1). Among patients with noncardia cancers, the body of stomach was the most common location of tumor in both familial (27\%) and sporadic patients (24\%). Tumor occurrence in the antrum of the stomach was slightly higher in familial patients (19\%), compared to sporadic patients $(15 \%)$ with gastric cancer.

In general, FDRs of patients with esophageal cancer had a 2.4-fold increased risk of this cancer compared to those without such a family history (Table 2). The familial risk of concordant location for lower third part of esophagus was 2.6-fold (SIR 2.6, 95\% CI 1.5-4.1).

We identified 932 patients with gastric cancer who had one gastric cancer patient among their FDRs (Table 3 ). The risk of gastric cancer increased by $60 \%$ in those with a family history of this cancer compared to those without such a family history (SIR 1.6, 95\% CI 1.5-1.7). Stratification by the location of the gastric cancer in FDRs showed increased overall risk of familial gastric cancer in those with a family history of gastric cancer in the antrum (SIR 2.1, 95\% CI 1.7-2.7), body (SIR 1.8, 95\% CI 1.4-2.2), pylorus (SIR 1.7, 95\% CI 1.1-2.5), and cardia (SIR 1.4, 95\% CI 1.2-1.6). An increased familial risk of gastric cancer in the same location of the stomach for one affected FDR was found in the antrum (SIR 5.5, 95\% CI 2.4-11), body (SIR 4.6, 95\% CI 2.6-7.4), or cardia (SIR 1.7, 95\% CI 1.1-2.5).

Increased risk of concordant adenocarcinoma of the stomach was seen for one affected FDR (SIR 1.6, 95\% CI 1.5-1.7, $\mathrm{n}=732$; data not shown), two affected FDRs (SIR 6.1, 95\% CI 4.4-8.4; $\mathrm{n}=38$; data not shown), and among twins (SIR 8.6, 95\% CI 2.3-22; n=4; data not shown). There was no familial 
Table I Basic characteristics in sporadic and familial patients with esophageal and gastric cancer (including in situ), Sweden, $1958-2015$.

\begin{tabular}{|c|c|c|c|c|c|c|c|}
\hline & \multicolumn{2}{|c|}{ Familial* } & \multicolumn{2}{|c|}{ Sporadic } & \multirow[t]{2}{*}{$P$-value } & \multicolumn{2}{|l|}{ Total } \\
\hline & $\overline{\mathbf{N}}$ & $\%$ & $\overline{\mathbf{N}}$ & $\%$ & & $\mathbf{N}$ & $\%$ \\
\hline Esophagus (N) & $15 \mid$ & & 13,174 & & & 13,325 & \\
\hline Sex & & & & & 0.352 & & \\
\hline Men & 106 & 70.2 & 9,691 & 73.6 & & 9,797 & 73.5 \\
\hline Women & 45 & 29.8 & 3,483 & 26.4 & & 3,528 & 26.5 \\
\hline Age at diagnosis, mean $( \pm S D)$ & 66.1 & $( \pm 10.4)$ & 69.0 & $( \pm 10.8)$ & 0.013 & 69.0 & $( \pm 10.8)$ \\
\hline$<50$ & 8 & 5.3 & 534 & 4.1 & & 542 & 4.1 \\
\hline $50-59$ & 33 & 21.9 & 1,955 & 14.8 & & 1,988 & 14.9 \\
\hline $60-69$ & 55 & 36.4 & 4,134 & 31.4 & & 4,189 & 31.4 \\
\hline $70-79$ & 39 & 25.8 & 4,277 & 32.5 & & 4,316 & 32.4 \\
\hline$\geq 80$ & 16 & 10.6 & 2,274 & 17.3 & & 2,290 & 17.2 \\
\hline Tumor location** & & & & & 0.330 & & \\
\hline Upper third & 6 & 7.8 & 626 & 10.7 & & 632 & 10.7 \\
\hline Middle third & 21 & 27.3 & 1,222 & 20.9 & & 1243 & 21.0 \\
\hline Lower third & 50 & 64.9 & 4,004 & 68.4 & & 4,054 & 68.4 \\
\hline Unspecified & 74 & & 7,322 & & & 7,396 & \\
\hline Stomach $(\mathrm{N})$ & 974 & & 49,681 & & & 50,655 & \\
\hline Sex & & & & & 0.025 & & \\
\hline Men & 592 & 60.8 & 31,929 & 64.3 & & 32,521 & 64.2 \\
\hline Women & 382 & 39.2 & 17,754 & 35.7 & & 18,136 & 35.8 \\
\hline Age at diagnosis mean $( \pm S D)$ & 65.1 & $( \pm 11.8)$ & 68.6 & $( \pm 12.2)$ & $<.001$ & 68.6 & $( \pm 12.2)$ \\
\hline$<50$ & 101 & 10.4 & 3,766 & 7.6 & & 3,867 & 7.6 \\
\hline $50-59$ & 186 & 19.1 & 6,982 & 14.1 & & 7,168 & 14.2 \\
\hline $60-69$ & 322 & 33.1 & 13,392 & 27.0 & & $|3,7| 4$ & 27.1 \\
\hline $70-79$ & 267 & 27.4 & 15,915 & 32.0 & & 16,182 & 31.9 \\
\hline$\geq 80$ & 98 & 10.1 & 9,624 & 19.4 & & 9,722 & 19.2 \\
\hline Tumor location** & & & & & 0.057 & & \\
\hline Cardia & 152 & 41.8 & 6,530 & 48.1 & & 6,682 & 47.9 \\
\hline Fundus & 14 & 3.8 & 676 & 5.0 & & 690 & 4.9 \\
\hline Body & 100 & 27.5 & 3,273 & 24.1 & & 3,373 & 24.2 \\
\hline Antrum & 71 & 19.5 & 2,106 & 15.5 & & 2,177 & 15.6 \\
\hline Pylorus & 27 & 7.4 & 995 & 7.3 & & 1022 & 7.3 \\
\hline Unspecified & 610 & & 36,101 & & & 36,711 & \\
\hline
\end{tabular}

Notes: *Familial patients include cases of multiple affected family members (38 cases had two first-degree relatives and four twins with stomach cancer; and three cases of multiple esophageal cancer in family); **Percentages are out of specified locations.

Table 2 Standardized incidence ratio (SIR) of esophageal and gastric cancers (including in situ) in a first-degree relative of a patient with esophageal cancer by tumor location.

\begin{tabular}{|c|c|c|c|c|c|c|c|c|c|c|c|c|c|c|c|c|}
\hline \multirow{4}{*}{$\begin{array}{l}\text { Cancer in } \\
\text { relative } \\
\text { Esophagus }\end{array}$} & \multicolumn{16}{|c|}{ Location of esophageal cancer in the patient in the family } \\
\hline & \multicolumn{4}{|c|}{ Upper third } & \multicolumn{4}{|c|}{ Middle third } & \multicolumn{4}{|c|}{ Lower third } & \multicolumn{4}{|l|}{ All } \\
\hline & \multirow{2}{*}{$\begin{array}{l}\mathbf{N} \\
6\end{array}$} & \multirow{2}{*}{$\begin{array}{l}\text { SIR } \\
1.7\end{array}$} & \multicolumn{2}{|c|}{$95 \% \mathrm{Cl}$} & \multirow{2}{*}{$\frac{\mathbf{N}}{21}$} & \multirow{2}{*}{$\frac{\text { SIR }}{3.4}$} & \multicolumn{2}{|c|}{$95 \% \mathrm{Cl}$} & \multirow{2}{*}{$\begin{array}{l}\mathbf{N} \\
49\end{array}$} & \multirow{2}{*}{$\begin{array}{l}\text { SIR } \\
2.3\end{array}$} & \multicolumn{2}{|c|}{$95 \% \mathrm{Cl}$} & \multirow{2}{*}{$\begin{array}{l}\mathbf{N} \\
148\end{array}$} & \multirow{2}{*}{$\frac{\text { SIR }}{2.4}$} & \multicolumn{2}{|c|}{$95 \% \mathrm{Cl}$} \\
\hline & & & 0.6 & 3.8 & & & 2.1 & 5.1 & & & 1.7 & 3.1 & & & 2.0 & 2.8 \\
\hline Upper third & 0 & & & & 0 & & & & 2 & 2.0 & 0.2 & 7.1 & 6 & 1.8 & 0.7 & 3.9 \\
\hline Middle third & 0 & & & & 0 & & & & 4 & 2.1 & 0.6 & 5.4 & 21 & 3.4 & 2.1 & 5.1 \\
\hline Lower third & 2 & 2.0 & 0.2 & 7.1 & 4 & 2.2 & 0.6 & 5.6 & 16 & 2.6 & 1.5 & 4.1 & 49 & 2.4 & 1.8 & 3.1 \\
\hline Stomach & 17 & 1.3 & 0.8 & 2.1 & 26 & 1.0 & 0.7 & 1.5 & 101 & $1.2^{*}$ & 1.0 & 1.5 & 240 & 1.1 & 1.0 & 1.3 \\
\hline Cardia & 2 & 1.2 & 0.2 & 4.4 & 4 & 1.3 & 0.4 & 3.3 & 18 & 1.7 & 1.0 & 2.7 & 51 & 1.7 & 1.2 & 2.2 \\
\hline Fundus & 1 & 6.2 & 0.2 & 34 & 1 & 3.2 & 0.1 & 18 & 0 & & & & 5 & 1.6 & 0.5 & 3.6 \\
\hline Body & 0 & & & & 0 & & & & 3 & 0.6 & 0.1 & 1.8 & 9 & 0.6 & 0.3 & I.I \\
\hline Antrum & 0 & & & & 0 & & & & 1 & 0.3 & 0.0 & 1.7 & 4 & 0.4 & 0.1 & 1.0 \\
\hline Pylorus & 0 & & & & 0 & & & & I & 0.7 & 0.0 & 3.7 & 2 & 0.5 & 0.1 & 1.7 \\
\hline
\end{tabular}

Notes: Bolded SIR=95\% Cl did not include I.00. Three esophageal cancer patients who had two first-degree relatives with esophageal cancer (SIR=10, 95\% CI 2.2-30) are not included in this table. *Example: Risk of stomach cancer (overall) in a first-degree relative of patients with the lower third esophageal cancer was I.2-fold higher than that in those without family history of esophageal cancer. 


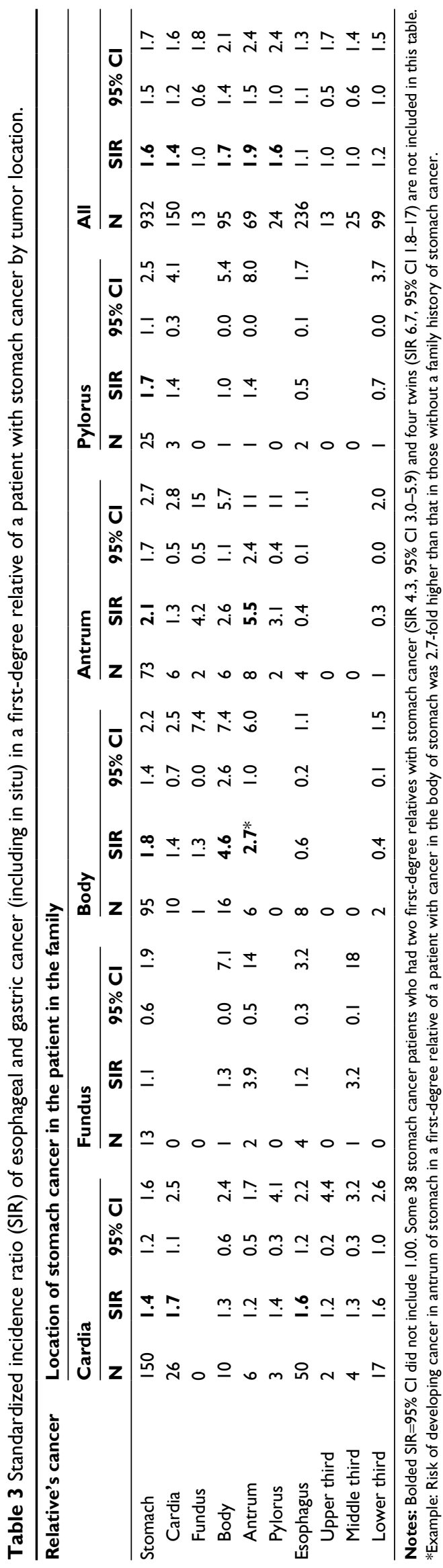

case of concordant gastric squamous cell carcinoma (SCC) in our database. Family history of cardia cancer was associated with an increased risk of esophageal adenocarcinoma (2.3fold, 95\% CI 1.5-3.4; $\mathrm{n}=28$; data not shown) and stomach SCC (11-fold, 95\% CI 3.0-28; n=4; data not shown). Moreover, we found that the occurrence of adenocarcinoma of esophageal cancer in one of the FDRs slightly increases the risk of gastric adenocarcinoma in other relatives (1.2-fold, 95\% CI 1.0-1.5; $\mathrm{n}=101$; data not shown), and a similar result was observed in reciprocal analyses (data not shown).

The occurrence of esophageal SCC in a family member was associated with an increased familial risk of developing similar histological cancer subtype in the esophagus (SIR $4.1,95 \%$ CI 3.2-5.2; Table 4) and stomach (SIR 7.8, 95\% CI 1.6-23; Table 4). Esophageal adenocarcinoma in an FDR was associated with an increased familial risk of the same subtype of esophageal tumor (SIR 3.6, 95\% CI 2.5-5.1). Adenocarcinoma constituted $89 \%$ of the familial gastric cancers.

\section{Discussion}

We found that the risk of esophageal cancer in FDRs of esophageal cancer patients increased 2.4-fold (SIR 95\% CI 2.0-2.8) and the risk of gastric cancer in FDRs increased 1.6-fold (1.5-1.7). It has been reported that offspring with a family history of esophageal and stomach cancer in one of their parents have a 2.5- and 1.7-fold higher risk for the concordant cancer, respectively. ${ }^{20}$ In the present study, using the latest update of the FCD (2015), we found a strong significantly increased familial risk for occurrence of cancer in concordant locations in the lower third of the esophagus (2.6-fold) and antrum (5.5-fold), body (4.6-fold), and cardia (1.7-fold) of the stomach among FDRs.

We found that family history of both adenocarcinoma and SCC histological subtype of esophageal cancer increased the familial risk of a concordant histological cancer subtype. Esophageal adenocarcinoma that mostly occurs in the lower third of esophagus has been established to be related to Barrett's esophagus, obesity, and GERD. ${ }^{12}$ Apart from the different etiology of SCC and adenocarcinoma, family history of both histological subtypes of esophageal cancer increased the familial risk of both subtypes. Derakhshan et al showed that columnar differentiation in the epithelium of lower esophagus, as a potential cause of esophageal adenocarcinoma, might be associated with central obesity and proximal extension of gastric acidity within the lower esophageal sphincter. ${ }^{21}$

Regardless of the tumor location, we observed that the occurrence of esophageal cancer in general in an FDR was 
Table 4 Standardized incidence ratio (SIR) of concordant and discordant histological subtypes of esophageal cancer (including in situ) among first-degree relatives

\begin{tabular}{|c|c|c|c|c|c|c|c|c|c|c|c|c|c|}
\hline \multirow{4}{*}{$\begin{array}{l}\text { Histology in relative } \\
\text { Esophagus (all) }\end{array}$} & \multicolumn{13}{|c|}{ Esophageal cancer histology in the patient in the family } \\
\hline & \multicolumn{4}{|c|}{ Adenocarcinoma } & \multicolumn{4}{|c|}{ Squamous cell carcinoma } & \multicolumn{4}{|c|}{ Other specified } & \multirow{3}{*}{$\begin{array}{l}\text { Unspecified } \\
\mathbf{N} \\
0\end{array}$} \\
\hline & \multirow{2}{*}{$\frac{\mathbf{N}}{52}$} & \multirow{2}{*}{$\frac{\text { SIR }}{2 . I}$} & \multicolumn{2}{|c|}{$95 \% \mathrm{Cl}$} & \multirow{2}{*}{$\frac{\mathbf{N}}{91}$} & \multirow{2}{*}{$\begin{array}{l}\text { SIR } \\
2.8\end{array}$} & \multicolumn{2}{|c|}{$95 \% \mathrm{Cl}$} & \multirow{2}{*}{$\begin{array}{l}\mathbf{N} \\
5\end{array}$} & \multirow{2}{*}{$\begin{array}{l}\text { SIR } \\
1.2\end{array}$} & \multicolumn{2}{|c|}{$95 \% \mathrm{Cl}$} & \\
\hline & & & 1.6 & 2.8 & & & 2.3 & 3.5 & & & 0.4 & 2.9 & \\
\hline Adenocarcinoma & 32 & 3.6 & 2.5 & 5.1 & 19 & 1.5 & 0.9 & 2.3 & I & 0.6 & 0.0 & 3.4 & 0 \\
\hline Squamous cell carcinoma & 19 & $1.5^{*}$ & 0.9 & 2.3 & 68 & 4.1 & 3.2 & 5.2 & 4 & 1.9 & 0.5 & 4.8 & 0 \\
\hline Other specified & 1 & 0.6 & 0.0 & 3.2 & 4 & 1.9 & 0.5 & 5.0 & 0 & & & & 0 \\
\hline Stomach (all) & 112 & 1.2 & 1.0 & 1.4 & 110 & 1.0 & 0.9 & 1.3 & 17 & 1.3 & 0.8 & 2.1 & 1 \\
\hline Adenocarcinoma & 103 & 1.2 & 1.0 & 1.5 & 95 & 1.0 & 0.8 & 1.3 & 16 & $\mathrm{I} .4$ & 0.8 & 2.2 & 1 \\
\hline Squamous cell carcinoma & 0 & & & & 3 & 7.8 & 1.6 & 23 & 0 & & & & 0 \\
\hline Other specified & 6 & 1.3 & 0.5 & 2.9 & 5 & 0.8 & 0.3 & 1.9 & 0 & & & & 0 \\
\hline
\end{tabular}

Notes: Bolded SIR=95\% Cl did not include 1.00. Upper gastrointestinal cancer patients who had >I first-degree relatives or twins with esophageal cancer are not included in this table. *Example: Risk of developing squamous cell carcinoma of esophagus in a first-degree relative of a patient with adenocarcinoma of esophagus was I.5-fold higher than in those without family history of esophageal cancer.

associated with an increased risk of esophageal cancer in other family members (2.4 times). Lagergren et al suggested that heredity does not seem to contribute significantly to any tumor location in esophageal cancer. ${ }^{22}$ Frank et al showed that the risk of esophageal cancer among spouses was higher than the familial risk and suggested that heritability may contribute less to the etiology of esophageal cancer than what is suggested by familial risk estimates. ${ }^{14}$ Regardless of the etiology of such a familial association (either shared environmental factors, lifestyle, or inheritance), we would suggest that particular attention should be paid to the esophagus during clinical investigation of patients with such a family history in their FDRs, especially if the family members had the cancer in the middle or lower third of the esophagus.

During recent decades, gastric cardia cancer has attracted attention among scientists and clinicians because of its steadily increasing trend worldwide. ${ }^{23,24}$ The rising incidence of cardia cancer has been associated with the epidemic of obesity, ${ }^{25}$ Western pattern of diet, ${ }^{26}$ and smoking. ${ }^{27}$ There are some observations suggesting that cardia gastric cancer may be associated with frequent GERD symptoms and atrophic gastritis. ${ }^{28,29} \mathrm{On}$ the basis of reports of similar changes in incidence trends of GERD-associated cardia gastric cancer and lower third esophageal cancer, it has been suggested that these two cancers share a similar etiology and pathophysiologic process. ${ }^{30}$ Results from an older version of the FCD showed familial association of cardia cancer with esophageal adenocarcinoma (in lower third) and suggested that they may have a common genetic basis. ${ }^{31}$ Furthermore, our data showed family history of cardia cancer was associated with a high risk of esophageal adenocarcinoma (2.3-fold, 95\% CI 1.5-3.4; n=28; data not shown) and stomach SCC (11-fold, 95\% CI 3.0-28; n=4; data not shown). Our study also showed that the occurrence of adenocarcinoma of esophageal cancer in one of the FDRs tended to increase the risk of gastric adenocarcinoma in other relatives (1.2-fold, 95\% CI 1.0-1.5; $\mathrm{n}=101$; data not shown) and a similar result was observed in reciprocal analyses (data not shown). There is some well-established evidence that GERD and Barrett's esophagus may have hereditary components ${ }^{12}$ and would likely shine through the pattern of occurrence of gastric cardia and lower esophageal cancers. ${ }^{22}$

The occurrence of non-cardia gastric cancer is mainly consistent with Helicobacter pylori-associated atrophic gastritis, which occurs predominantly in distal parts of the stomach. ${ }^{29}$ The degree of antral atrophy is similar among $H$. pylori-infected patients whereas the degree of body atrophy is variable among $H$. pylori-infected patients including both less atrophic and severely atrophic changes. The similarity of atrophic degree leads to a high risk of gastric cancer in the antrum. The variability of atrophic degree leads to a lower risk in the gastric body than in the antrum. The Asia Pacific 2008 consensus guidelines on gastric cancer prevention recommended $H$. pylori screening and treatment to reduce gastric cancer development in high-risk populations. ${ }^{32}$ We showed that FDRs of patients with gastric cancer in the body, antrum, and pylorus of the stomach have a 1.7- to 2.1-fold higher risk for developing gastric cancer, especially in the same location for the body (4.6-fold) and antrum (5.5-fold). These findings are in-line with some large-scale case-control studies which indicated that the risk of gastric cancer in the body of the stomach is higher in patients with a family history of gastric cancer in their parents. ${ }^{33}$ These findings may address some putative genetic predisposition for developing gastric cancer in these 
parts of the stomach, although it could be also due to $H$. pylori acquisition in the familial environment in childhood. European Guidelines on $H$. pylori infection management strongly recommend bacterium eradication in FDRs of patients with gastric cancer. ${ }^{34}$

The database used in this study is the largest of its kind in the world, and risk estimates generated by this data are relatively precise. The sporadic reference population likely contained smaller family sizes than the familial population; however, based on our previous study, family size does not influence cancer risk. ${ }^{35}$ Although there were cases with unspecified tumor location in our database, we believe that such missing data have been non-differential with regard to estimated familial risks and our findings based on specified locations are valid. Familial UGI cancers can be due to both shared genetic and environmental factors, however, the strength of this study is that estimated familial risks can be used in the clinic regardless of the exact underlying reason for them. Our findings may potentially have an effect on clinical practice with regard to screening for relatives of patients with a family history of UGI cancers in some specific locations such as the lower third of the esophagus and the cardia, body, and antrum of the stomach, which showed very high familial risk for a concordant location.

\section{Conclusion}

In brief, the current study provides highly valid populationbased evidence that a positive family history of UGI cancer in specific anatomical locations is a predictor of concordant and some discordant tumors in FDRs of these patients. Estimated familial risks from this study can be used in the clinic regardless of the exact underlying reason for them. Gastroenterologists should be aware of the high risk of these cancers in these specific locations in FDRs of UGI cancer patients. This information is important as it may have practical implications on early detection of these cancers, which in turn might affect survival of these patients. Large etiological studies are warranted to identify genetic and other possible risk factors that resulted in these findings.

\section{Acknowledgments}

This work was supported by the German Cancer Research Center visiting scientist program, German Cancer Aid, and the EU Transcan funding by the German Federal Ministry of Education and Research.

\section{Disclosure}

The authors report no conflicts of interest in this work.

\section{References}

1. Ferlay J, Soerjomataram I, Dikshit R, et al. Cancer incidence and mortality worldwide: sources, methods and major patterns in GLOBOCAN 2012. Int J Cancer. 2015;136(5):E359-E386.

2. Kamangar F, Dores GM, Anderson WF. Patterns of cancer incidence, mortality, and prevalence across five continents: defining priorities to reduce cancer disparities in different geographic regions of the world. J Clin Oncol. 2006;24(14):2137-2150.

3. Jemal A, Center MM, DeSantis C, Ward EM. Global patterns of cancer incidence and mortality rates and trends. Cancer Epidemiol Biomarkers Prev. 2010;19(8):1893-1907.

4. Arnold M, Moore SP, Hassler S, Ellison-Loschmann L, Forman D, Bray F. The burden of stomach cancer in indigenous populations: a systematic review and global assessment. Gut. 2014;63(1):64-71.

5. Hosokawa O, Miyanaga T, KaizakiY, et al. Decreased death from gastric cancer by endoscopic screening: association with a population-based cancer registry. Scand J Gastroenterol. 2008;43(9):1112-1115.

6. Hamashima C, Okamoto M, Shabana M, Osaki Y, Kishimoto T. Sensitivity of endoscopic screening for gastric cancer by the incidence method. Int J Cancer. 2013;133(3):653-659.

7. Choi IJ. Endoscopic gastric cancer screening and surveillance in highrisk groups. Clin Endosc. 2014;47(6):497-503.

8. Machida-Montani A, Sasazuki S, Inoue M, et al. Association of Helicobacter pylori infection and environmental factors in non-cardia gastric cancer in Japan. Gastric Cancer. 2004;7(1):46-53.

9. Holster IL, Aarts MJ, Tjwa ET, Lemmens VE, Kuipers EJ. Trend breaks in incidence of non-cardia gastric cancer in the Netherlands. Cancer Epidemiol. 2014;38(1):9-15.

10. Yu J, Zhao Q. The demographic characteristics of histological types of gastric cancer with gender, age, and tumor location. $J$ Gastrointest Cancer. 2009;40(3-4):98-100.

11. Karimi P, Islami F, Anandasabapathy S, Freedman ND, Kamangar F. Gastric cancer: descriptive epidemiology, risk factors, screening, and prevention. Cancer Epidemiol, Biomarkers Prev. 2014;23(5): 700-713.

12. Verbeek RE, Spittuler LF, Peute A, et al. Familial clustering of Barrett's esophagus and esophageal adenocarcinoma in a European cohort. Clin Gastroenterol Hepatol. 2014;12(10):1656-1663.e1.

13. Mousavi SM, Sundquist K, Hemminki K. Does the risk of stomach cancer remain among second-generation immigrants in Sweden? Gastric Cancer. 2012;15(2):213-215.

14. Frank C, Fallah M, Ji J, Sundquist J, Hemminki K. The population impact of familial cancer, a major cause of cancer. Int $J$ Cancer. 2014;134(8):1899-1906.

15. Dhillon PK, Farrow DC, Vaughan TL, et al. Family history of cancer and risk of esophageal and gastric cancers in the United States. Int $J$ Cancer. 2001;93(1):148-152.

16. Ji J, Hemminki K. Familial risk for esophageal cancer: an updated epidemiologic study from Sweden. Clin Gastroenterol Hepatol. 2006;4(7):840-845.

17. Hemminki K, Li X. Familial risks of cancer as a guide to gene identification and mode of inheritance. Int J Cancer. 2004;110(2):291-294.

18. Hemminki K, Ji J, Brandt A, Mousavi SM, Sundquist J. The Swedish Family-Cancer Database 2009: prospects for histology-specific and immigrant studies. Int J Cancer. 2010;126(10):2259-2267.

19. Barlow L, Westergren K, Holmberg L, Talbäck M. The completeness of the Swedish Cancer Register: a sample survey for year 1998. Acta Oncol. 2009;48(1):27-33.

20. Frank C, Fallah M, Sundquist J, Hemminki A, Hemminki K. Population landscape of familial cancer. Sci Rep. 2015;5:12891.

21. Derakhshan MH, Robertson EV, Lee YY, et al. In healthy volunteers, immunohistochemistry supports squamous to columnar metaplasia as mechanism of expansion of cardia, aggravated by central obesity. Gut . 2015;64(11):1705-1714.

22. Lagergren J, Ye W, Lindgren A, Nyrén O. Heredity and risk of cancer of the esophagus and gastric cardia. Cancer Epidemiol, Biomarkers Prev. 2000;9(7):757-760. 
23. He YT, Hou J, Chen ZF, et al. Trends in incidence of esophageal and gastric cardia cancer in high-risk areas in China. Eur J Cancer Prev. 2008;17(2):71-76.

24. Dubecz A, Solymosi N, Stadlhuber RJ, Schweigert M, Stein HJ, Peters $\mathrm{JH}$. Does the incidence of adenocarcinoma of the esophagus and gastric cardia continue to rise in the twenty-first century?-a SEER database analysis. J Gastrointest Surg. 2014;18(1):124-129.

25. Sinh P, Sharma P. Gastric cardia cancer: how much is it from fat? Dig Dis Sci. 2012;57(10):2493-2496.

26. Bahmanyar S, Ye W. Dietary patterns and risk of squamous-cell carcinoma and adenocarcinoma of the esophagus and adenocarcinoma of the gastric cardia: a population-based case-control study in Sweden. Nutr Cancer. 2006;54(2):171-178.

27. Navarro Silvera SA, Mayne ST, Gammon MD, et al. Diet and lifestyle factors and risk of subtypes of esophageal and gastric cancers: classification tree analysis. Ann Epidemiol. 2014;24(1):50-57.

28. Hansen S, Vollset SE, Derakhshan MH, et al. Two distinct aetiologies of cardia cancer; evidence from premorbid serological markers of gastric atrophy and Helicobacter pylori status. Gut. 2007;56(7): 918-925.
29. Derakhshan MH, Malekzadeh R, Watabe H, et al. Combination of gastric atrophy, reflux symptoms and histological subtype indicates two distinct aetiologies of gastric cardia cancer. Gut. 2008;57(3):298-305.

30. Abrams JA, Gonsalves L, Neugut AI. Diverging trends in the incidence of reflux-related and Helicobacter pylori-related gastric cardia cancer. J Clin Gastroenterol. 2013;47(4):322-327.

31. Hemminki K, Sundquist J, Ji J. Familial risk for gastric carcinoma: an updated study from Sweden. Brit J Cancer. 2007;96(8):1272-1277.

32. Fock KM, Talley N, Moayyedi P, et al; Asia-Pacific Gastric Cancer Consensus Conference. Asia-Pacific consensus guidelines on gastric cancer prevention. J Gastroenterol Hepatol. 2008;23(3):351-365.

33. Eto K, Ohyama S, Yamaguchi T, et al. Familial clustering in subgroups of gastric cancer stratified by histology, age group and location. Eur J Surg Oncol. 2006;32(7):743-748.

34. Zagari RM, Romano M, Ojetti V, et al. Guidelines for the management of Helicobacter pylori infection in Italy: the III Working Group Consensus Report 2015. Dig Liver Dis. 2015;47(11):903-912.

35. Hemminki K, Mutanen P. Birth order, family size, and the risk of cancer in young and middle-aged adults. Br J Cancer. 2001;84(11): 1466-1471. 


\section{Supplementary materials}

When we excluded the esophageal and gastric in situ tumors from analyses, our results did not change substantially (Tables S1-S4).

Table SI Basic characteristics in sporadic and familial patients with invasive esophageal and gastric cancer, Sweden, 1958-20I5.

\begin{tabular}{|c|c|c|c|c|c|c|c|}
\hline & \multicolumn{2}{|c|}{ Familial* } & \multicolumn{2}{|c|}{ Sporadic } & \multirow[t]{2}{*}{$P$-value } & \multicolumn{2}{|l|}{ Total } \\
\hline & $\mathbf{N}$ & $\%$ & $\mathbf{N}$ & $\%$ & & $\overline{\mathbf{N}}$ & $\%$ \\
\hline Esophagus (N) & 130 & & 12,510 & & & 12,640 & \\
\hline Sex & & & & & 0.333 & & \\
\hline Men & 91 & 70.0 & 9,227 & 73.8 & & 9,318 & 73.7 \\
\hline Women & 39 & 30.0 & 3,283 & 26.2 & & 3,322 & 26.3 \\
\hline Age at diagnosis, mean $( \pm S D)$ & 66.4 & $( \pm 10.5)$ & 69.0 & $( \pm 10.8)$ & 0.119 & 68.9 & $( \pm 10.8)$ \\
\hline$<50$ & 7 & 5.4 & 491 & 3.9 & & 498 & 3.9 \\
\hline $50-59$ & 28 & 21.5 & $\mathrm{I}, 874$ & 15.0 & & 1,902 & 15.0 \\
\hline $60-69$ & 43 & 33.1 & 3,970 & 31.7 & & 4,013 & 31.7 \\
\hline $70-79$ & 37 & 28.5 & 4,039 & 32.3 & & 4,076 & 32.2 \\
\hline$\geq 80$ & 15 & 11.5 & 2,136 & I7.1 & & $2,15 \mid$ & 17.0 \\
\hline Tumor location** & & & & & 0.062 & & \\
\hline Upper third & 5 & 7.9 & 602 & 10.9 & & 607 & 10.9 \\
\hline Middle third & 21 & 33.3 & $\mathrm{I}, 170$ & 21.2 & & 1191 & 21.4 \\
\hline Lower third & 37 & 58.7 & 3,739 & 67.8 & & 3,776 & 67.7 \\
\hline Unspecified & 67 & & 6,999 & & & 7,066 & \\
\hline Stomach $(\mathrm{N})$ & 907 & & 48,089 & & & 48,996 & \\
\hline Sex & & & & & 0.037 & & \\
\hline Men & 554 & 61.1 & 30,983 & 64.4 & & 31,537 & 64.4 \\
\hline Women & 353 & 38.9 & 17,104 & 35.6 & & 17,457 & 35.6 \\
\hline Age at diagnosis, mean $( \pm S D)$ & 65.1 & $( \pm I I .8)$ & 68.5 & $( \pm 12.2)$ & $<0.001$ & 68.5 & $( \pm 12.2)$ \\
\hline$<50$ & 94 & 10.4 & 3,664 & 7.6 & & 3,758 & 7.7 \\
\hline $50-59$ & 174 & 19.2 & 6,818 & 14.2 & & 6,992 & 14.3 \\
\hline $60-69$ & 299 & 33.0 & $|3,06|$ & 27.2 & & 13,360 & 27.3 \\
\hline $70-79$ & 250 & 27.6 & 15,383 & 32.0 & & 15,633 & 31.9 \\
\hline$\geq 80$ & 90 & 9.9 & 9,163 & 19.1 & & 9,253 & 18.9 \\
\hline Tumor location** & & & & & 0.011 & & \\
\hline Cardia & 145 & 42.0 & 6,352 & 48.8 & & 6,497 & 48.6 \\
\hline Fundus & 11 & 3.2 & 640 & 4.9 & & 651 & 4.9 \\
\hline Body & 93 & 27.0 & 3,097 & 23.8 & & 3,190 & 23.9 \\
\hline Antrum & 71 & 20.6 & 1,975 & 15.2 & & 2,046 & 15.3 \\
\hline Pylorus & 25 & 7.2 & 953 & 7.3 & & 978 & 7.3 \\
\hline Unspecified & 562 & & 35,072 & & & 35,634 & \\
\hline
\end{tabular}

Notes: *Familial patients include cases of multiple affected family members ( 4 I cases had $\geq 2$ first-degree relatives with stomach cancer; and two cases of multiple esophageal cancer in family); **Percentages are out of specified locations.

Table S2 Standardized incidence ratio (SIR) of invasive esophageal and gastric cancers in a first-degree relative of a patient with esophageal cancer by tumor location

\begin{tabular}{|c|c|c|c|c|c|c|c|c|c|c|c|c|c|c|c|c|}
\hline \multirow{4}{*}{$\begin{array}{l}\text { Cancer in } \\
\text { relative } \\
\text { Esophagus }\end{array}$} & \multicolumn{16}{|c|}{ Location of esophageal cancer in the patient in the family } \\
\hline & \multicolumn{4}{|c|}{ Upper third } & \multicolumn{4}{|c|}{ Middle third } & \multicolumn{4}{|c|}{ Lower third } & \multicolumn{4}{|l|}{ All } \\
\hline & \multirow{2}{*}{$\begin{array}{l}\mathbf{N} \\
5\end{array}$} & \multirow{2}{*}{$\begin{array}{l}\text { SIR } \\
1.6\end{array}$} & \multicolumn{2}{|c|}{$95 \% \mathrm{Cl}$} & \multirow{2}{*}{$\begin{array}{l}\mathbf{N} \\
21\end{array}$} & \multirow{2}{*}{$\begin{array}{l}\text { SIR } \\
3.7\end{array}$} & \multicolumn{2}{|c|}{$95 \% \mathrm{Cl}$} & \multirow{2}{*}{$\begin{array}{l}\mathbf{N} \\
37\end{array}$} & \multirow{2}{*}{$\begin{array}{l}\text { SIR } \\
2.0\end{array}$} & \multicolumn{2}{|c|}{$95 \% \mathrm{Cl}$} & \multirow{2}{*}{$\begin{array}{l}\mathbf{N} \\
128\end{array}$} & \multirow{2}{*}{$\begin{array}{l}\text { SIR } \\
2.3\end{array}$} & \multicolumn{2}{|c|}{$95 \% \mathrm{Cl}$} \\
\hline & & & 0.5 & 3.7 & & & 2.3 & 5.6 & & & 1.4 & 2.7 & & & 1.9 & 2.7 \\
\hline Upper third & 0 & & & & 0 & & & & 2 & 2.2 & 0.3 & 7.9 & 5 & 1.6 & 0.5 & 3.8 \\
\hline Middle third & 0 & & & & 0 & & & & 3 & 1.8 & 0.4 & 5.1 & 21 & 3.6 & 2.2 & 5.5 \\
\hline Lower third & 2 & 2.2 & 0.3 & 8.0 & 3 & 1.8 & 0.4 & 5.3 & 10 & 1.8 & 0.9 & 3.3 & 37 & 2.0 & 1.4 & 2.8 \\
\hline Stomach & 14 & I.I & 0.6 & 1.9 & 24 & 1.0 & 0.7 & 1.5 & 90 & $1.2^{*}$ & 0.9 & 2.5 & 209 & I.I & 0.9 & 1.2 \\
\hline Cardia & 2 & 1.3 & 0.2 & 4.7 & 4 & $\mathrm{I} .4$ & 0.4 & 3.6 & 15 & 1.5 & 0.9 & 2.5 & 44 & 1.5 & I.I & 2.1 \\
\hline Fundus & 0 & & & & 0 & & & & 0 & & & & 3 & 1.0 & 0.2 & 3.0 \\
\hline Body & 0 & & & & 0 & & & & 3 & 0.7 & 0.1 & 2.0 & 7 & 0.5 & 0.2 & I.I \\
\hline Antrum & 0 & & & & 0 & & & & I & 0.4 & 0.0 & 1.9 & 4 & 0.4 & 0.1 & I.I \\
\hline Pylorus & 0 & & & & 0 & & & & I & 0.7 & 0.0 & 4.1 & 1 & 0.3 & 0.0 & 1.4 \\
\hline
\end{tabular}

Notes: Bolded SIR=95\% Cl did not include I.00; *Example: Risk of stomach cancer (overall) in a first-degree relative of patients with the lower third esophageal cancer was I.2-fold higher than that in those without a family history of esophageal cancer. 


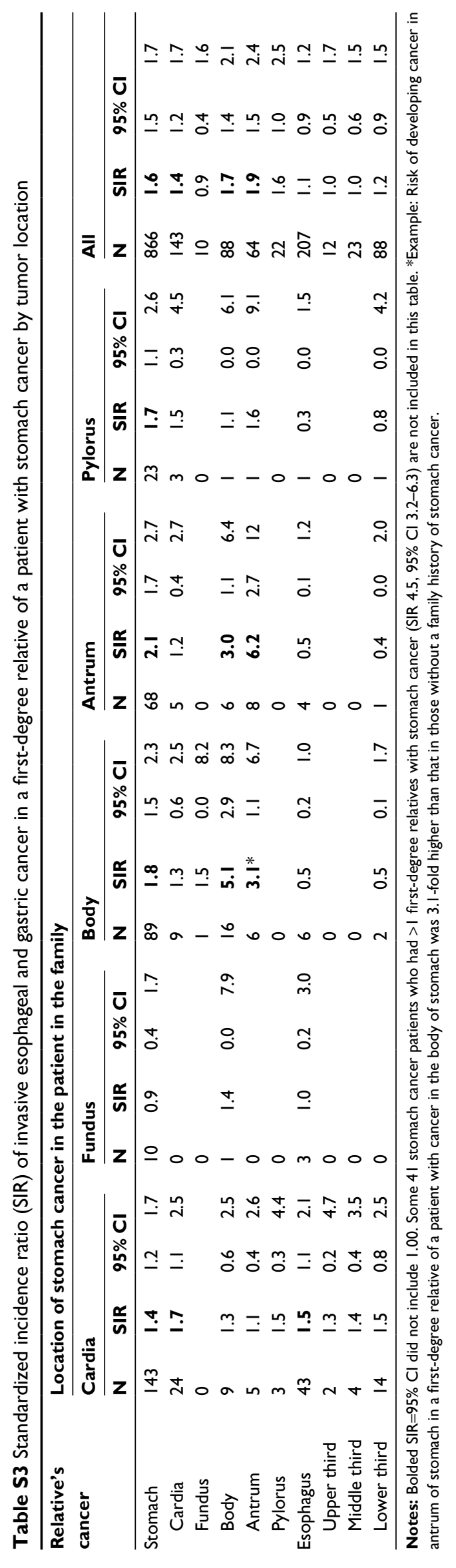


Table S4 Standardized incidence ratio (SIR) of concordant and discordant histological subtypes of invasive esophageal cancer among first-degree relatives

\begin{tabular}{|c|c|c|c|c|c|c|c|c|c|c|c|c|c|}
\hline \multirow{4}{*}{$\begin{array}{l}\text { Histology in relative } \\
\text { Esophagus (all) }\end{array}$} & \multicolumn{13}{|c|}{ Esophageal cancer histology in the patient in the family } \\
\hline & \multicolumn{4}{|c|}{ Adenocarcinoma } & \multicolumn{4}{|c|}{ Squamous cell carcinoma } & \multicolumn{4}{|c|}{ Other specified } & \multirow{3}{*}{$\begin{array}{l}\text { Unspecified } \\
\mathbf{N} \\
0\end{array}$} \\
\hline & \multirow{2}{*}{$\frac{\mathbf{N}}{42}$} & \multirow{2}{*}{$\begin{array}{l}\text { SIR } \\
2.0\end{array}$} & \multicolumn{2}{|c|}{$95 \% \mathrm{Cl}$} & \multirow{2}{*}{$\frac{\mathbf{N}}{82}$} & \multirow{2}{*}{$\begin{array}{l}\text { SIR } \\
2.8\end{array}$} & \multicolumn{2}{|c|}{$95 \% \mathrm{Cl}$} & \multirow{2}{*}{$\begin{array}{l}\mathbf{N} \\
4\end{array}$} & \multirow{2}{*}{$\begin{array}{l}\text { SIR } \\
1.0\end{array}$} & \multicolumn{2}{|c|}{$95 \% \mathrm{Cl}$} & \\
\hline & & & 1.4 & 2.6 & & & 2.2 & 3.5 & & & 0.3 & 2.7 & \\
\hline Adenocarcinoma & 24 & 3.1 & 2.0 & 4.6 & 17 & 1.5 & 0.9 & 2.4 & 1 & 0.7 & 0.0 & 3.7 & 0 \\
\hline Squamous cell carcinoma & 17 & $1.5^{*}$ & 0.8 & 2.3 & 50 & 4.0 & 3.1 & 5.1 & 3 & 1.5 & 0.3 & 4.3 & 0 \\
\hline Other specified & 1 & 0.6 & 0.0 & 3.5 & 3 & 1.5 & 0.3 & 4.5 & 0 & & & & 0 \\
\hline Stomach (all) & 96 & 1.1 & 0.9 & 1.4 & 95 & 1.0 & 0.8 & 1.2 & 17 & 1.4 & 0.8 & 2.2 & I \\
\hline Adenocarcinoma & 89 & 1.2 & 1.0 & 1.5 & 83 & 1.0 & 0.8 & 1.2 & 16 & 1.4 & 0.8 & 2.2 & I \\
\hline Squamous cell carcinoma & 0 & & & & 3 & 8.9 & 1.8 & 26 & 0 & & & & 0 \\
\hline Other specified & 6 & 1.7 & 0.6 & 3.7 & 4 & 0.8 & 0.2 & 2.0 & 0 & & & & 0 \\
\hline
\end{tabular}

Notes: Bolded SIR=95\% Cl did not include 1.00. Upper gastrointestinal cancer patients who had $>$ I first-degree relatives with esophageal cancer are not included in this table. *Example: Risk of developing squamous cell carcinoma of esophagus in a first-degree relative of a patient with adenocarcinoma of esophagus was I.5-fold higher than that in those without a family history of esophageal cancer.

Clinical Epidemiology is an international, peer-reviewed, open access, online journal focusing on disease and drug epidemiology, identification of risk factors and screening procedures to develop optimal preventative initiatives and programs. Specific topics include: diagnosis, prognosis, treatment, screening, prevention, risk factor modification,

\section{Dovepress}

systematic reviews, risk and safety of medical interventions, epidemiology and biostatistical methods, and evaluation of guidelines, translational medicine, health policies and economic evaluations. The manuscript management system is completely online and includes a very quick and fair peer-review system, which is all easy to use. 